\title{
Multiple characteristics optimization in machining of GFRP composites using Grey relational analysis
}

\author{
Arun Kumar Parida, Rajesh Kumar Bhuyan and Bharat Chandra Routara*
}

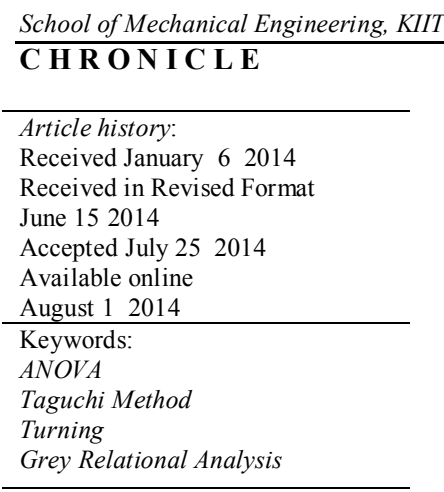

\section{Introduction}

The use of machining such as turning, drilling, milling, etc. in GFRP composite is increasing as the field of application of composite is quite a lot. However, it is often made difficult to machine the GFRP composites as it brings many undesirable results such as rapid tool wear, a defective surface layer with cracks or delamination, a rough surface finish etc. To avoid this problem, it is necessary to select the appropriate process parameters to get the highest performance for desired dimensional accuracy. Davim and Mata (2004) studied the influencing parameters on surface roughness during turning of GFRP using statistical analysis. They reported the percentage of contribution of cutting parameters such as velocity and feed rate on the surface roughness. Surface roughness of unidirectional GFRP composite was experimented by Iş1k (2008) on the basis of process parameters such as cutting speed, feed, depth of cut and tool geometry in turning with CERMET cutting tool and found that the surface quality is closely related with speed, feed and tool geometry. Palanikumar (2006) used Taguchi method, which offers a simple and systematic approach to find the optimum cutting parameters for surface roughness. Hence, from the literature (Santhanakrishnan, 1990; Sakuma \& Seto, 1983; Takeyama \& Iijima, 1988; Sang-Ook et al., 1997) a detailed analysis has been carried out for identifying the important parameters, which affects the machining characteristics. Taguchi method is a scientifically disciplined mechanism for evaluating and implementing the improvement in products, processes, materials and facilities.

* Corresponding author.

E-mail: bcroutray@gmail.com (B. C. Routara)

(C) 2014 Growing Science Ltd. All rights reserved. doi: $10.5267 /$ j.jijiec.2014.8.001 
These improvements are aimed at improving the desired characteristics and simultaneously reducing the number of defects by studying the key variables controlling the process and optimizing the procedures or design to yield the best results (1996). However, this method is designed to optimize a single performance characteristics and difficult to optimize the multi-responses in complex process (1989). Deng (1989) proposed a Grey relational theory which is useful for solving the problems with poor, insufficient and uncertain information. It can be further effectively adopted for solving the complicated interrelationship among the designated performance characteristics. The grey relational theory provides a better solution in which the information is incomplete or the model is incomplete (1989). It also provides an efficient solution to the uncertainty, multiple inputs and discrete data problem (2004). Using Grey relational analysis, Tzeng and Chen (2006) optimized the process parameters in turning of tool steels with eight numbers of independent variables. They determined the optimum parameters, which maximizes the accuracy and minimizes the surface roughness and dimensional precision. Palanikumar et al. (2006) employed orthogonal array with Grey relational analysis to optimize the multiple performance characteristics in turning of GFRP with cemented carbide (k-10) tool. According to them the Grey relational theory simplifies the optimization procedure. It is also economical and more convenient to predict the effect of different influencing combinations of parameters. Gupta and Kumar (2013) applied successfully the Grey relational theory to optimize the process parameters in multiple performance characteristics such as surface roughness and material removal rate during turning of GFRP with Poly-crystalline diamond cutting tool. Rao et al. (2012) used Grey relational analysis for optimizing the multi- response characteristics to minimize the surface roughness and cutting force and maximize the tool life in machining of Inconel-718 with process parameters such as speed, feed, depth of cut and approach angle. From the above studies, it is found that Grey relational analysis is one of the important techniques for optimizing the multi-response characteristics and it can be applied successfully to any machining process.

In this present work, an experimental investigation has been carried out using a normal speed lathe machine. The experiments were carried out on the basis of Taguchi's $L_{9}$ orthogonal array. The important turning parameters were chosen as spindle speed, feed rate and depth of cut. The multiple responses such as surface roughness and material removal rate are analyzed here. The Grey relational analysis is used to optimize multi objective responses. ANOVA is also used to find the highly influencing machining parameters that contribute to high quality product. Finally, confirmation tests are conducted to validate the experimental results.

\section{Experimental work}

The GFRP work-pieces having $40 \mathrm{~mm}$ diameter and $50 \mathrm{~mm}$ in length are used for machining in a lathe. The GFRP bar was fabricated by dry hand lay-up technique. The hand lay-up technique was chosen as it was ideally suited to manufacture low volume with minimum tooling cost. The experiments were planned using Taguchi's $L_{9}$ orthogonal array that helps to reduce the number of experimental runs. The three cutting parameters such as spindle speed, feed rate and depth of cut with three different levels are used for the experimentation. The turning experiments were carried out in an all geared lathe machine whose spindle speed ranges from 200 to $400 \mathrm{rpm}$ and feed ranges from 0.03 to $0.05 \mathrm{~mm} / \mathrm{rev}$. The machining of wok-pieces was carried out in a dry condition with cemented carbide tool. The composition of fiber, resin and filler and the machining parameters with their levels are shown in Table 1 and Table 2.

\subsection{Material Removal Rate (MRR)}

The material removal rate is the volume of material removed per unit time. Volume of material removed is a function of spindle speed, feed rate and depth of cut. Material removal with a higher rate is one of the most important criteria during the turning operation. The $M R R$ is calculated using the expression 
$\mathrm{MRR}=\pi D_{i} d f \mathrm{~N}$ in $\mathrm{mm}^{3} / \mathrm{min}$,

where $D_{i}$ is the initial diameter, $d$ is the depth of cut, $f$ is the feed rate and $N$ is the number of revolutions of spindle per minute.

\subsection{Surface Roughness $\left(R_{a}\right)$}

Surface roughness is also another important aspect in machining of GFRP composite. Here the roughness is measured three times using a stylus type surface roughness tester(Taylor Hobson, Sutronic 25) of sampling length $0.8 \mathrm{~mm}$, evaluation length of $4 \mathrm{~mm}$ and least count of $0.01 \mu \mathrm{m}$ and the average surface roughness is listed in Table 2.

Table 1

Specification of epoxy, filler and fiber

\begin{tabular}{lccc}
\hline Sl. No. & Epoxy + Hardener & Filler & E-glass \\
\hline 01 & Araldite LY 556 & Graphite (3 wt \%) & R099 1200 P566 (44 wt \%) \\
& + & + & \\
& HY 951(50 wt \%) & Ash clay (3 wt \%) & \\
\hline
\end{tabular}

Table 2

Machining parameters with their levels

\begin{tabular}{ccccccccc}
\hline Expt. no & $N$ & $f$ & $d$ & $\begin{array}{c}N \\
(\mathrm{rpm})\end{array}$ & $\begin{array}{c}f \\
(\mathrm{~mm} / \mathrm{rev})\end{array}$ & $\begin{array}{c}d \\
(\mathrm{~mm})\end{array}$ \\
\hline 01 & 1 & 1 & 1 & 200 & 0.03 & 0.5 & 319.49 \\
roughness $R_{a}$ \\
in $(\mu \mathrm{m})$
\end{tabular}

\section{Optimization of individual performance characteristics}

\subsection{Determination of optimal process parameters for MRR}

In this section, $L_{9}$ orthogonal array is used to determine the optimal process parameters. Machining results are reported in using $\mathrm{S} / \mathrm{N}$ ratio and ANOVA analysis. In Taguchi method, there are three performance characteristics such as higher-is-better, nominal-is-better and lower-is-better. Here higheris-better characteristic is used to find the optimal process parameter for $M R R$. The $M R R$ and $\mathrm{S} / \mathrm{N}$ ratio for $M R R$ is listed in Table 3.

Table 3

Experimental results for $M R R$ and $\mathrm{S} / \mathrm{N}$ ratio

\begin{tabular}{cccccc}
\hline Run & $N$ & $f$ & $d$ & MRR & S/N ratio \\
\hline 01 & 1 & 1 & 1 & 319.49 & 50.0891 \\
02 & 1 & 2 & 2 & 625.80 & 55.9287 \\
03 & 1 & 3 & 3 & 913.26 & 59.2119 \\
04 & 2 & 1 & 2 & 1071.28 & 60.5981 \\
05 & 2 & 2 & 3 & 1455.08 & 63.2577 \\
06 & 2 & 3 & 1 & 493.13 & 53.8592 \\
07 & 3 & 1 & 3 & 1074.42 & 67.5786 \\
08 & 3 & 2 & 1 & 2111.15 & 60.6235 \\
09 & 3 & 3 & 2 & & 66.4904 \\
\hline
\end{tabular}




\subsection{Analysis of $S / N$ ratio for $M R R$}

As the experimental design is orthogonal, so it is possible to separate out the effect of each process parameter at different levels. From the response Table 4 of mean $\mathrm{S} / \mathrm{N}$ ratio for $M R R$, the optimal process parameters are obtained such as spindle speed at level-3, feed rate at level-2 and depth of cut at level-3 i.e., $v_{3}-f_{2}-d_{3}$.

\section{Table 4}

Response table of mean $\mathrm{S} / \mathrm{N}$ ratio for $M R R$

\begin{tabular}{|c|c|c|c|c|c|c|}
\hline \multirow[t]{2}{*}{ Symbol } & \multirow{2}{*}{$\begin{array}{c}\text { Process } \\
\text { parameters }\end{array}$} & \multicolumn{4}{|c|}{ Mean S/N ratio } & \multirow[t]{2}{*}{ Rank } \\
\hline & & Level-1 & Level-2 & Level-3 & Max-Min & \\
\hline$N$ & Spindle speed & 55.08 & 59.24 & 64.90 & 9.82 & 1 \\
\hline$f$ & Feed rate & 59.42 & 59.94 & 59.85 & 0.51 & 3 \\
\hline$d$ & Depth of cut & 54.86 & 61.01 & 63.35 & 8.49 & 2 \\
\hline
\end{tabular}

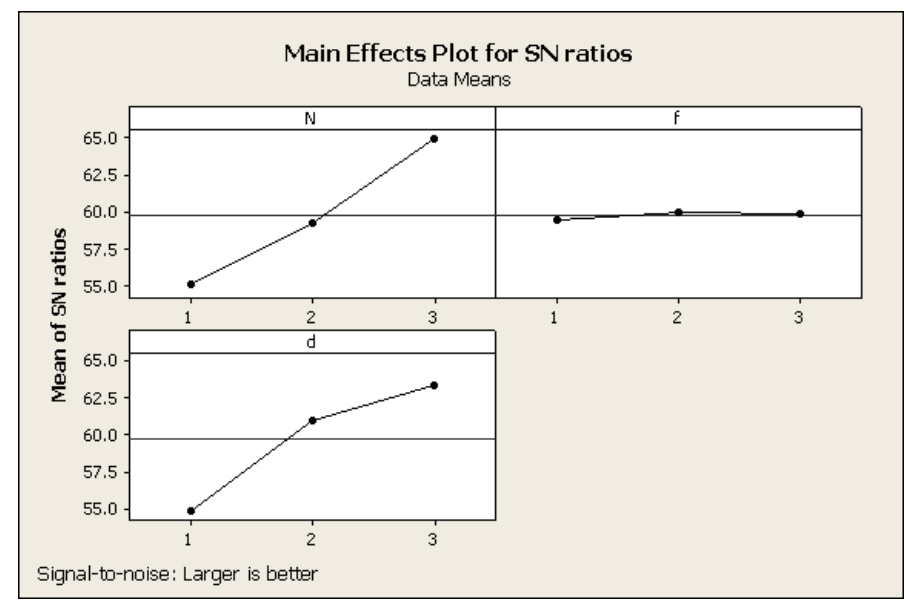

Fig. 1. Mean $\mathrm{S} / \mathrm{N}$ graph for $M R R$

\subsection{ANOVA for MRR}

The purpose of the ANOVA is to find the statistical significance of process parameters on the response shown in Table 5. From table, it is found that spindle speed with a P-value less than 0.05 that means it is significant at $95 \%$ confidence level. Therefore, spindle speed is the most significant parameter for $M R R$.

Table 5

ANOVA table for $M R R$

\begin{tabular}{cccccc}
\hline Source & DF & SS & MS & F & P \\
\hline$N$ & 2 & 2414913 & 1207456 & 21.13 & 0.045 \\
$f$ & 2 & 66325 & 33163 & 0.58 & 0.633 \\
Error & 2 & 1428931 & 714465 & 5.50 & 0.074 \\
\hline Total & 2 & 114269 & 57134 & & \\
\hline
\end{tabular}

$\mathrm{S}=239.028 \quad \mathrm{R}-\mathrm{Sq}=97.16 \% \quad \mathrm{R}-\mathrm{Sq}(\operatorname{adj})=88.64 \%$

\subsection{Confirmation test for MRR}

Confirmation tests are carried out using the optimal process parameter combination to predict and verify the improvement of the performance characteristics as shown in Table 6. Here the increase of $\mathrm{S} / \mathrm{N}$ ratio from the initial process parameter to optimal process parameter is $18.0186 \mathrm{~dB}$ and based on the confirmation test, $M R R$ is increased 7.96 times. 
Table 6

Results of confirmation for $M R R$

\begin{tabular}{cccc} 
& Initial process parameter & Optimal process parameter \\
\cline { 3 - 4 } & & Prediction & Experiment \\
\hline Level & $N_{1}-f_{l}-d_{1}$ & & $N_{3}-f_{2}-d_{3}$ \\
$M R R$ & 319.49 & & 2543.21 \\
S/N ratio $(\mathrm{dB})$ & 50.0891 & 68.7086 & 68.1076 \\
\hline
\end{tabular}

Improvement of $\mathrm{S} / \mathrm{N}$ ratio $=18.0186 \mathrm{~dB}$

\subsection{Determination of optimal process parameters for surface roughness $\left(R_{a}\right)$}

Similarly, the $\mathrm{S} / \mathrm{N}$ ratio for surface roughness is calculated. Here lower-is-better characteristic is used to find the optimal process parameter for surface roughness $\left(R_{a}\right)$. The $\mathrm{S} / \mathrm{N}$ ratio for $R_{a}$ is listed in Table 7. From the response Table 8 of mean $\mathrm{S} / \mathrm{N}$ ratio for $R_{a}$, the optimal process parameters are obtained such as spindle speed at level-1, feed rate at level-1 and depth of cut at level-3 i.e., $N_{1-}-f_{1}-d_{3}$.

Table 7

Experimental results for surface roughness and $\mathrm{S} / \mathrm{N}$ ratio

\begin{tabular}{cccccc}
\hline Run & $v$ & $f$ & $d$ & $R_{a}$ & S/N ratio \\
\hline 01 & 1 & 1 & 1 & 2.60 & -8.2995 \\
02 & 1 & 2 & 2 & 2.80 & -8.9432 \\
03 & 1 & 3 & 3 & 2.00 & -6.0206 \\
04 & 2 & 1 & 2 & 2.50 & -7.9588 \\
05 & 2 & 2 & 3 & 2.80 & -8.9432 \\
06 & 2 & 3 & 1 & 3.40 & -10.6296 \\
07 & 3 & 1 & 3 & 3.52 & -10.9309 \\
08 & 3 & 2 & 1 & 4.88 & -13.7684 \\
09 & 3 & 3 & 2 & 3.44 & -10.7312 \\
\hline
\end{tabular}

\subsection{Analysis of $S / N$ ratio for surface roughness $\left(R_{a}\right)$}

Table 8

Response table of mean $\mathrm{S} / \mathrm{N}$ ratio for $R_{a}$

\begin{tabular}{|c|c|c|c|c|c|c|}
\hline \multirow[t]{2}{*}{ Symbol } & \multirow{2}{*}{$\begin{array}{c}\text { Process } \\
\text { parameters }\end{array}$} & \multicolumn{4}{|c|}{ Mean $\mathrm{S} / \mathrm{N}$ ratio } & \multirow[t]{2}{*}{ Rank } \\
\hline & & Level-1 & Level-2 & Level-3 & Max-Min & \\
\hline$N$ & Spindle speed & -7.754 & -9.177 & -11.810 & 4.056 & $\overline{1}$ \\
\hline$f$ & Feed rate & -9.063 & -10.552 & -9.127 & 1.489 & 3 \\
\hline$d$ & Depth of cut & -10.899 & -9.211 & -8.632 & 2.268 & 2 \\
\hline
\end{tabular}

Total mean $\mathrm{S} / \mathrm{N}$ ratio $=-9.580 \mathrm{~dB}$

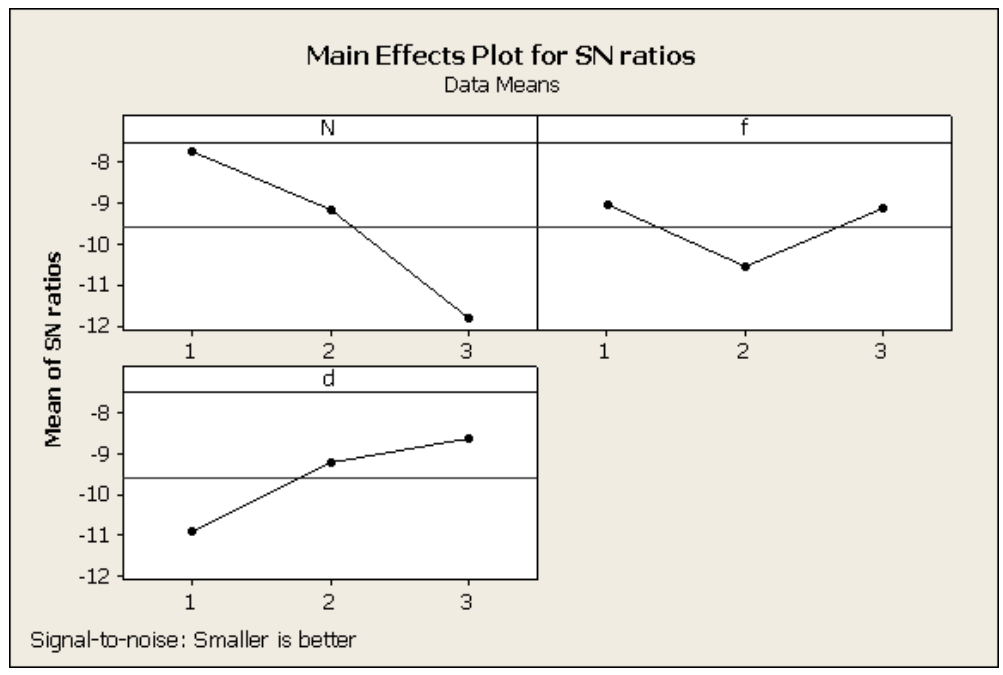

Fig. 2. Mean $\mathrm{S} / \mathrm{N}$ graph for surface roughness 
3.7 ANOVA for surface roughness $\left(R_{a}\right)$

ANOVA for surface roughness $\left(R_{a}\right)$ is listed in the Table 9. From the table it is clearly found that spindle speed with a P- value less than 0.05 that means it is significant at $95 \%$ confidence level. Therefore, spindle speed is the most significant parameter for $R_{a}$ followed by depth of cut and feed rate.

Table 9

ANOVA table for surface roughness $\left(R_{a}\right)$

\begin{tabular}{cccccc}
\hline Source & DF & SS & MS & F & P \\
\hline$N$ & 2 & 3.47369 & 1.73684 & 26.46 & 0.036 \\
$f$ & 2 & 0.68862 & 0.34431 & 5.25 & 0.160 \\
$d$ & 2 & 1.25662 & 0.62831 & 9.57 & 0.095 \\
Error & 2 & 0.13129 & 0.06564 & & \\
\hline Total & 8 & 5.55022 & & &
\end{tabular}

\subsection{Confirmation test for surface roughness $\left(R_{a}\right)$}

In the confirmation table for surface roughness $\left(R_{a}\right)$, it is found that the increase of $\mathrm{S} / \mathrm{N}$ ratio from the initial process parameters to the optimal process parameters is $2.7244 \mathrm{~dB}$ which is shown in Table 10 . Based on the confirmation test it is also found that the surface roughness is increased 1.36 times.

Table 10

Results of confirmation for surface roughness $\left(R_{a}\right)$

\begin{tabular}{|c|c|c|c|}
\hline \multirow{2}{*}{\multicolumn{2}{|c|}{ Initial process parameter }} & \multicolumn{2}{|c|}{ Optimal process parameters } \\
\hline & & Prediction & Experiment \\
\hline Level & $N_{1}-f_{1}-d_{1}$ & & $N_{1}-f_{1}-d_{3}$ \\
\hline$R_{a}$ & 2.60 & & 1.9 \\
\hline $\mathrm{S} / \mathrm{N}$ ratio $(\mathrm{dB})$ & -8.2995 & -6.28783 & -5.5751 \\
\hline
\end{tabular}

Improvement of $\mathrm{S} / \mathrm{N}$ ratio $=2.7244 \mathrm{~dB}$

\section{Grey relational analysis}

The grey relational analysis, which is useful for dealing with poor, incomplete and uncertain information can be used to solve complicated inter-relationships among multiple performance characteristics satisfactorily. Following are the steps needed for converting the multi-response characteristics to single response characteristics.

1) Normalize the experimental results of metal removal rate and surface roughness(data preprocessing)

2) Calculate the Grey relational co-efficient.

3) Calculate the Grey relational grade by averaging the Grey relational co-efficient.

In the grey relational analysis, the experimental results are first normalized in the range between zero and unity. This process of normalization is known as the grey relational generation. After then the grey relational coefficient is calculated from the normalized experimental data to express the relationship between the desired and actual experimental data. Then, the overall grey relational grade is calculated by averaging the grey relational coefficient corresponding to each selected process response. The overall evaluation of the multiple process responses are based on the grey relational grade. This method converts a multiple response process optimization problem with the objective function of overall grey relational grade. The corresponding level of parametric combination with highest grey relational grade is considered as the optimum process parameter.

In the grey relational analysis, the normalized data processing for surface roughness $\left(R_{a}\right)$ corresponding to lower-the-better criterion is expressed as 
$\mathrm{x}_{\mathrm{i}}(\mathrm{k})=\frac{\operatorname{maxy}_{\mathrm{i}}(\mathrm{k})-\mathrm{y}_{\mathrm{i}}(\mathrm{k})}{\operatorname{maxy}_{\mathrm{i}}(\mathrm{k})-\operatorname{miny}_{\mathrm{i}}(\mathrm{k})}$

In the turning operation, the material removal rate should be higher. Therefore the normalized data processing for the material removal rate is the higher-the-better performance characteristics considered and is expressed as

$$
\mathrm{x}_{\mathrm{i}}(\mathrm{k})=\frac{\mathrm{y}_{\mathrm{i}}(\mathrm{k})-\operatorname{miny}_{\mathrm{i}}(\mathrm{k})}{\max _{\mathrm{i}}(\mathrm{k})-\operatorname{miny}_{\mathrm{i}}(\mathrm{k})}
$$

Eq. (1) is used for the "lower-the-better" responses and Eq. (2) is used for the "larger-the- better" responses, where $x_{i}(k)$ is the value after grey relational generation, min $y_{i}(k)$ is the smallest value of $\mathrm{y}_{\mathrm{i}}(\mathrm{k})$ for the $\mathrm{k}_{\mathrm{th}}$ response, and the $\max \mathrm{y}_{\mathrm{i}}(\mathrm{k})$ is the largest value of $\mathrm{y}_{\mathrm{i}}(\mathrm{k})$ for the $\mathrm{k}_{\text {th }}$ response. An ideal sequence is $\mathrm{x}_{0}(\mathrm{k})$ where $\left(\mathrm{k}=1,2\right.$ for $M R R$ and $R_{a}$ respectively). The definition of grey relational grade in the course of grey relational analysis is to reveal the relational degree between the nine sequences $\left[\mathrm{x}_{\mathrm{o}}(\mathrm{k})\right.$ and $\left.\mathrm{x}_{\mathrm{i}}(\mathrm{k}), \mathrm{i}=1,2,3 \ldots . .9\right]$. The grey relational coefficient $\xi_{i}(k)$ can be calculated as

$$
\xi_{i}(k)=\frac{\Delta_{\min }+\psi \Delta_{\max }}{\Delta_{o i}(k)+\psi \Delta_{\max }},
$$

where $\Delta_{o i}=x_{o}(k)-x_{i}(k)=$ difference of the absolute value between $\mathrm{x}_{\mathrm{o}}(\mathrm{k})$ and $\mathrm{x}_{\mathrm{i}}(\mathrm{k})$;

$\Psi=$ distinguishing coefficient between zero and one, the purpose of which is to weaken the effect of $\Delta_{\max }$ when it gets too big, and thus enlarges the difference significance of the relational coefficient. In the present case, $\psi=0.5$ is used.

After averaging the grey relational coefficients, the grey relational grade $\gamma_{i}$ can be calculated as follows:

$$
\gamma_{i}=\frac{1}{n} \sum_{k=1}^{n} \xi_{i}(k),
$$

where $n=$ number of process responses. The higher value of grey relational grade is considered as the stronger relational degree between the ideal sequence $x_{0}(k)$ and the given sequence $x_{i}(k)$. It has already been mentioned that the ideal sequence $x_{0}(k)$ is the best process response in the experimental layout. The higher grey relational grade implies that the corresponding parameter combination is closer to the optimal. Thus, the grey relational grade is found out which is shown in Table 11.

\begin{tabular}{|c|c|c|c|c|c|c|c|c|c|}
\hline \multirow[t]{2}{*}{$\begin{array}{c}\text { Expt. } \\
\text { No }\end{array}$} & \multicolumn{2}{|c|}{ Responses } & \multicolumn{2}{|c|}{ Grey relational generation } & \multicolumn{2}{|c|}{ Evaluation of $\Delta_{\mathrm{oi}}$} & \multicolumn{2}{|c|}{$\begin{array}{c}\text { Grey relational } \\
\text { coefficient }(\psi=0.5)\end{array}$} & \multirow{2}{*}{$\begin{array}{l}\text { Grey } \\
\text { relational } \\
\text { grade }\end{array}$} \\
\hline & $M R R$ & $R_{a}$ & $M R R$ & $R_{a}$ & $M R R$ & $R_{a}$ & $M R R$ & $R_{a}$ & \\
\hline 01 & 319.49 & 2.6 & 0 & 0.791667 & 1 & 0.208333 & 0.333333 & 0.705882 & 0.519608 \\
\hline 02 & 625.8 & 2.8 & 0.099664 & 0.722222 & 0.900336 & 0.277778 & 0.357057 & 0.642857 & 0.499957 \\
\hline 03 & 913.26 & 2 & 0.193195 & 1 & 0.806805 & 0 & 0.382612 & 1 & 0.691306 \\
\hline 04 & 1071.28 & 2.5 & 0.244609 & 0.826389 & 0.755391 & 0.173611 & 0.398282 & 0.742268 & 0.570275 \\
\hline 05 & 1555.08 & 2.8 & 0.402023 & 0.722222 & 0.597977 & 0.277778 & 0.455383 & 0.642857 & 0.54912 \\
\hline 06 & 493.13 & 3.4 & 0.056497 & 0.513889 & 0.943503 & 0.486111 & 0.34638 & 0.507042 & 0.426711 \\
\hline 07 & 3392.92 & 3.52 & 1 & 0.472222 & 0 & 0.527778 & 1 & 0.486486 & 0.743243 \\
\hline 08 & 1074.42 & 4.88 & 0.245631 & 0 & 0.754369 & 1 & 0.398607 & 0.333333 & 0.36597 \\
\hline 09 & 2111.15 & 3.44 & 0.582951 & 0.5 & 0.417049 & 0.5 & 0.545227 & 0.5 & 0.522614 \\
\hline
\end{tabular}

\section{Table 11}

Grey relational grade table 


\subsection{Determination of optimal process parameters for Grey relational grade}

Table 12

$\mathrm{S} / \mathrm{N}$ ratio and grey relational grade of performance characteristics

\begin{tabular}{cccccc}
\hline Run & $N$ & $f$ & $d$ & Grey-relational grade & S/N ratio \\
\hline 01 & 1 & 1 & 1 & 0.519608 & -5.68648 \\
02 & 1 & 2 & 2 & 0.499957 & -6.02135 \\
03 & 1 & 3 & 3 & 0.691306 & -3.20659 \\
04 & 2 & 1 & 2 & 0.570275 & -4.87831 \\
05 & 2 & 2 & 3 & 0.54912 & -5.20665 \\
06 & 2 & 3 & 1 & 0.426711 & -7.39732 \\
07 & 3 & 1 & 3 & 0.743243 & -2.57738 \\
08 & 3 & 2 & 1 & 0.36597 & -8.73109 \\
09 & 3 & 3 & 2 & 0.522614 & -5.63638 \\
\hline
\end{tabular}

\subsection{Analysis of S/N ratio for Grey relational grade}

Table 13

Response table of mean $\mathrm{S} / \mathrm{N}$ ratio for Grey relational grade

\begin{tabular}{ccccccc}
\hline \multirow{2}{*}{ Symbol } & Process & \multicolumn{2}{c}{ Mean S/N ratio } & \multicolumn{2}{c}{ Rank } \\
\cline { 3 - 6 } & parameters & Level-1 & Level-2 & Level-3 & Max-Min & 3 \\
& Spindle speed & -4.971 & -5.827 & -5.648 & 0.856 & 2 \\
$f$ & Feed rate & -4.381 & -6.653 & -5.413 & 2.272 & 3.608 \\
\hline$d$ & Depth of cut & -7.272 & -5.512 & -3.664 & & 1 \\
\hline
\end{tabular}

Total mean $\mathrm{S} / \mathrm{N}$ ratio $=-5.482 \mathrm{~dB}$

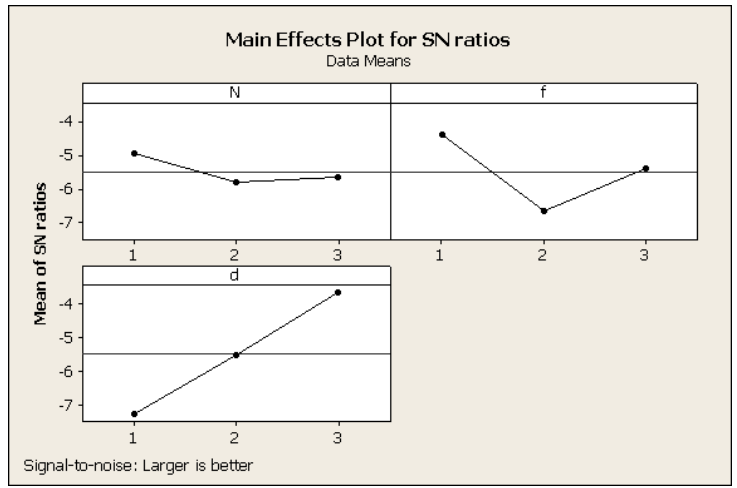

Fig. 3. Grey relational grade graph of multiple performance characteristics

The optimal process parameters are obtained from the response graph as shown in Fig 3. The optimal setting parameters for multiple performance characteristics is spindle speed at level-1, feed rate at level-1 and depth of cut at level-3 i.e. $N_{1-} f_{1}-d_{3}$.

\subsection{ANOVA for Grey relational grade}

From the table it is clearly found that depth of cut with a P-value less than 0.05 that means it is significant at $95 \%$ confidence level. So depth of cut is the most significant parameter for $R_{a}$ followed by feed rate and spindle speed for multiple performance characteristics.

\section{Table 14}

ANOVA for grey relational grade

\begin{tabular}{cccccc}
\hline Source & DF & SS & MS & F & P \\
\hline$N$ & 2 & 0.004527 & 0.002264 & 4.39 & 0.185 \\
$f$ & 2 & 0.029193 & 0.014596 & 28.32 & 0.034 \\
$d$ & 2 & 0.075801 & 0.037900 & 73.53 & 0.013 \\
Error & 2 & 0.001031 & 0.000515 & & \\
\hline Total & 8 & 0.110551 & & & \\
\hline
\end{tabular}

$\mathrm{S}=0.0227041 \quad \mathrm{R}-\mathrm{Sq}=99.07 \% \quad \mathrm{R}-\mathrm{Sq}(\mathrm{adj})=96.27 \%$ 
4.4 Confirmation test for Grey relational grade

Table 15

Results for the confirmation tests

\begin{tabular}{|c|c|c|c|}
\hline \multirow{2}{*}{\multicolumn{2}{|c|}{ Initial process parameter }} & \multicolumn{2}{|c|}{ Optimal process parameter } \\
\hline & & Prediction & experimen \\
\hline Level & $N_{1}-f_{1}-d_{1}$ & $N_{1}-f_{1}-d_{3}$ & $N_{1}-f_{1}-d_{3}$ \\
\hline$M R R$ & 319.49 & & 1885.08 \\
\hline$R_{a}$ & 2.6 & & 2.5 \\
\hline Grey relational Grade & 0.519608 & -2.05095 & 0.623505 \\
\hline
\end{tabular}

After the optimum level of machining parameters in multiple performance characteristics is identified, a verification test needs to be carried out in order to check the accuracy of the analysis. Table 15 shows the comparison of estimated grey relational grade with the actual grey relational grade obtained in experiment using the optimal cutting parameters. It is also found that the improvement of grey relational grade from initial process parameter combination to the optimal process parameter combination is 0.10 .

\section{Conclusions}

The use of the Taguchi orthogonal array with grey relational analysis to optimize the machining process with the multiple performance characteristics is reported here. A grey relational analysis of the experimental results of $M R R$ and surface roughness are converted to single performance characteristics called the grey relational grade. As a result, optimization of the complicated multiple performance characteristics can be greatly simplified through this approach. It is shown that the performance characteristic of the machining process such as $M R R$ and surface roughness are improved together by using this approach. Finally, the suggested multi-response approach using grey relational analysis in combination with Taguchi's robust design methodology is quite capable for any type of optimization problem involving any number of responses.

\section{References}

Davim, J. P., \& Mata, F. (2004). Influence of cutting parameters on surface roughness in turning glassfibre-reinforced plastics using statistical analysis. Industrial Lubrication and Tribology, 56(5), 270274.

Deng, J. L. (1989). Introduction to Grey system. Journal of Grey System, 1, 1-24.

Gupta, M. \& Kumar, S. (2013). Multi-objective optimization of cutting parameters in turning using grey relational analysis. International Journal of Industrial Engineering Computations, (4), 547558.

Iş1k, B. (2008). Experimental investigations of surface roughness in orthogonal turning of unidirectional glass-fiber reinforced plastic composites. The International Journal of Advanced Manufacturing Technology, 37(1-2), 42-48.

Palanikumar, K. (2006). Cutting parameters optimization for surface roughness in machining of GFRP composites using Taguchi's method. Journal of Reinforced Plastics and Composites, 25(16), 17391751.

Palanikumar, K., Karunamoorthy, L., \& Karthikeyan, R. (2006). Multiple performance optimization of machining parameters on the machining of GFRP composites using carbide (K10) tool. Materials and Manufacturing Processes,21(8), 846-852.

Ross, P. J. (1996). Taguchi Techniques for Quality Engineering, McGraw-Hill, New York.

Sadasiva, R., Rajesh V. \& Venu Gopal. A. (2012). Taguchi based Grey Relational Analysis to optimize face milling process with multiple performance characteristics. International Conference on Trends in Industrial and Mechanical Engineering, Dubai, (ICTIME), March 24-25.

Sakuma, K. \& Seto, M. (1983) Tool wear in cutting glass-fiber-reinforced plastics (the relation between fiber orientation and tool wear). Bulletin of the JSME. 26 (218), 1420-1427. 
Sang-Ook, A., Eun-Sang, L. \& Sang-Lai, N. (1997). A study on the cutting characteristics of glass fiber reinforced plastics with respect to tool materials and geometries. Journal of Materials Processing Technology, 68, 60-67.

Santhanakrishnan, G. (1990). Investigations on machining of FRP composites and their Tribological Behaviour. PhD thesis, IIT Madras: Chennai, India.

Singh, N. P., Raghukandan, K. \& Pai, P. C. (2004). Optimization by Grey Relational Analysis of EDM Parameters on Machining Al-10\% SICP Composites. Journal of Materials Processing Technology, 155-156, 1658-1661.

Takeyama, H., \& Iijima, N. (1988). Machinability of glassfiber reinforced plastics and application of ultrasonic machining. CIRP Annals-Manufacturing Technology, 37(1), 93-96.

Tzeng, Y. F., \& Chen, F. C. (2006). Multi-objective process optimization for turning of tool steels. International Journal of Machining and Machinability of Materials, 1(1), 76-93. 